\title{
REVOLUÇÕES DE DIREITA NA EUROPA DO ENTRE-GUERRAS: O FASCISMO E O NAZISMO
}

Right-wing revolutions in Europe between

the world wars: fascism and nazism

Las revoluciones de derecha en Europa del

entreguerras: el fascismo y el nazismo

Denise RollemberG

http://dx.doi.org/10.1590/S2178-14942017000200004

Denise Rollemberg é mestre e doutora em História pela Universidade Federal Fluminense e professora de História Contemporânea na mesma instituição (deniserollemberg@uol.com.br).

Artigo recebido em 31 de janeiro e aprovado para publicação em 26 de abril de 2017. 


\title{
RESUMO
}

0 artigo pretende discutir a pertinência ou não do uso do conceito de revolução para movimentos e regimes de direita e mesmo de extrema-direita a partir da Itália fascista e da Alemanha nacional socialista. Examina as principais correntes sobre o tema, cotejando historiadores importantes na citada polêmica, assim como certos discursos das lideranças fascista e nazista.

PALAVRAS-CHAVE: revolução; contrarrevolução; fascismo; nazismo.

\begin{abstract}
The article intends to discuss the pertinence or not of the use of the concept of revolution for right wing and even extreme right wing movements and regimes from the fascist Italy and the national socialist Germany. It examines the main currents on the subject, comparing important historians in the aforementioned polemic, as well as certain discourses of the fascist and nazi leaderships.
\end{abstract}

KEYwORDs: revolution; counterrevolution; fascism; nazism.

\section{RESUMEN}

Este artículo discute la pertinencia o no del uso del concepto revolución para movimientos y regímenes de derecha y extrema derecha de la Italia fascista y de la Alemania nacionalsocialista. Examina las principales tendencias en ese tema, en comparación con importantes historiadores en la mencionada controversia, así como ciertos discursos de los líderes fascistas y nazistas.

Palabras Clave: revolución; contrarrevolución; fascismo; nazismo. 


\section{O CONCEITO DE REVOLUÇÃO E SUA APLICABILIDADE} AOS REGIMES ITALIANO E ALEMÃO

É possível chamar de revolução projetos, movimentos, regimes de direita e mesmo de extrema-direita, ou o conceito deve se restringir a projetos, movimentos e regimes de esquerda?

Os grandes eventos que enfrentaram o Antigo Regime e as forças de sua restauração, entre os séculos XVIII e XIX, marcaram o conceito moderno de revolução. ${ }^{1}$ Como ocorreu com relação às Revoluções Americana (1776) e Francesa (1789), ligou-se o termo revolução "à noção de que o curso da História começa subitamente de um novo rumo, de que uma História inteiramente nova, uma História nunca antes conhecida ou narrada está para se desenrolar" (Arendt, 1988: 23).

No esforço para compreender a Revolução Francesa, historiadores do século XIX cunharam o conceito de revolução burguesa (Hobsbawm, 2006: 54). Tratava-se da geração imediatamente seguinte a ela, identificada com o liberalismo triunfante, o que thes valeu a qualificação de "historiadores liberais" (Hobsbawm, 2006; Kershaw, 1997). ${ }^{2}$ Entre os vários acontecimentos e processos que marcaram as revoluções burguesas no século XIX, a experiência francesa tornou-se o caso clássico. ${ }^{3}$

Marx incorporou o conceito de revolução burguesa nas suas análises. No Manifesto do Partido Comunista, de 1848, ao descrever a situação que sacudia a Europa de então, destacou o "papel eminentemente revolucionário" desempenhado pela burguesia na investida contra o Antigo Regime (Marx, s/d: 23). Poucos anos depois, no célebre 018 brumário, escrito em 1852, afirmou sem rodeios: "Centro do feudalismo na Idade Média e país modelo da monarquia unitária estamental desde o Renascimento, a França pulverizou o feudalismo na grande revolução e instaurou a dominação pura da burguesia sob uma forma clássica como nenhum país da Europa" (Marx, 2003: 9). ${ }^{4}$

A leitura marxista do conceito foi amplamente difundida na Segunda Internacional Socialista, criada em 1889, e teve papel fundamental na formulação das revoluções socialistas que pretendia fomentar. Marx considerava a revolução burguesa uma etapa necessária para a revolução socialista e, por conseguinte, para o triunfo da sociedade comunista. Afinada com essa perspectiva à esquerda, a compreensão do que seria revolução ganhou o século XX. 
Um traço comum entre a concepção liberal e a marxista do conceito de revolução burguesa reside no valor positivo atribuído à revolução: para o primeiros, porque ela derrubara o Antigo Regime; para o pensador alemão, porque abria caminho para a vitória de uma sociedade igualitária, comunista.

No cerne da interpretação de Marx de revolução, seja a burguesa seja a socialista, a chave residia, conceitual e historicamente, na transformação do modo de produção em colapso e na derrubada subsequente da ordem política que era por ele sustentada e que, simultaneamente, a sustentava. Marx reafirmou, portanto, ao menos implicitamente, a tese do determinismo econômico como fator explicativo da transformação social. Isto não significa, pelo contrário, que tenha desprezado a complexidade da mudança ou dos processos revolucionários burgueses, em particular a luta de classes e suas repercussões políticas. Em certos textos, ele procurou justamente iluminar o que Fernand Braudel chamou, um século depois, de tempo curto da história: o tempo quente dos episódios e das lutas sociais concretas (Braudel, 1992).

É o caso do citado 018 brumário de Luís Bonaparte, escrito no calor da hora, entre dezembro de 1851 e março de 1852, para explicar a derrubada da Monarquia de Julho em 1848, seguido em 1852, na França oitocentista. Publicado originalmente em alemão, na revista Die Revolution, o texto foi reeditado algumas vezes no século XIX e ainda o é até hoje. Os episódios da história francesa entre 1848 e 1852 são interpretados por Marx antes de tudo como um golpe contrarrevolucionário, inscrito em um longo processo de ascensão das classes populares na França desde 1789. "Por que o proletariado não se levantou em 5 de dezembro de 1852?", indaga-se Marx (2003: 103), superestimando a força das classes populares francesas durante o golpe bonapartista, mas nem tanto, considerando a irrupção da Comuna de Paris em 1871.

0 mesmo se pode dizer dos diversos artigos que Marx publicou na imprensa norte-americana e europeia, bem como da vasta correspondência, inclusive com Abraham Lincoln, durante a Guerra Civil dos Estados Unidos (1861-1865), conflito que opôs o capitalismo liberal do Norte ao escravismo sulista. São textos preciosos, portadores de análises de grande acuidade no campo da política e da guerra, independentemente do parti pris do autor, para quem o significado da vitória nortista na Guerra Civil residia no avanço do capitalismo, na consolidação do proletariado urbano, na erradicação da escravidão e mesmo no engajamento dos ex-escravos na classe trabalhadora do país, para o que considerava fundamental o combate aos preconceitos raciais. Em texto de 1861, dedicado a interpretar a eclosão da guerra, Marx afirmou:

Se é verdade que o Norte, depois de longas hesitações, e de exibir uma paciência desconhecida nos anais da história da Europa, empunhou finalmente a espada, não para esmagar a escravidão, mas para salvar a União, o Sul, por sua parte, inaugurou a guerra proclamando 'a 
instituição peculiar' como o fim único e principal da rebelião. Confessou lutar pela liberdade de escravizar outras pessoas, uma liberdade que, apesar dos protestos do Norte, afirmou ser posta em perigo pela vitória do Partido Republicano e a eleição do Sr. Lincoln para a cadeira presidencial (Marx, $1972: 53-54) .^{5}$

Análise arguta, não apenas das motivações da guerra, afinal deflagrada pelos escravistas, mas também dos discursos políticos em confronto, com destaque para o empenho dos sulistas em "lutar por sua liberdade de escravizar outras pessoas". É caso de lastimar, portanto, que os historiadores marxistas, em sua maioria, não tenham percebido o potencial de Marx com analista político das lutas políticas e ideológicas, ancorando-se apenas em sua teoria geral.

Seja como for, os autores marxistas descartaram, no século XX, o uso do conceito de revolução para definir os processos históricos desencadeados por movimentos, por vezes transformados em regimes políticos, que não resultaram em mudanças radicais na estrutura de classes, por não terem implicado, nem tampouco incentivado, a mudança do modo de produção. Na melhor das hipóteses, entre os marxistas, é possível encontrar, em Hobsbawm (1995: 121), a síntese reveladora das contradições do debate: "Os fascistas eram os revolucionários da contra-revolução". ${ }^{6}$ Em uma frase, o historiador consegue alcançar a ação revolucionária dos fascistas e negar, ao mesmo tempo, que houvessem protagonizado qualquer revolução.

Neste sentido, o fascismo e o nazismo, surgidos na Europa saída da Grande Guerra, alcançando o poder na Itália em 1922 e na Alemanha em 1933, foram conceituados como movimentos de contrarrevolução, regimes contrarrevolucionários. ${ }^{7} 0$ argumento baseou-se em que, além de apoiados pela burguesia do grande capital, tais movimentos, nos respectivos países, opuseram-se visceralmente às revoluções socialistas que sacudiram a Europa, a começar pela Revolução Bolchevique na Rússia, triunfante em 1917, pela Revolução Alemã, derrotada em 1919, e pela explosão de movimentos sociais revolucionários nas cidades e no campo na Itália, entre a primavera de 1919 e o fim de 1920. Da mesma forma, como se sabe, o fascismo e o nazismo gestaram-se na recusa dos valores liberais consagrados pelas revoluções burguesas. Nem por isso esses movimentos antibolcheviques e antidemocráticos abriram mão do conceito de revolução, pensado como processo de transformação positiva da ordem vigente. Interpretar as transformações propostas ou implementadas pelos dois regimes como revolução poderia indicar a sua aprovação e a sua legitimação.

De fato, os discursos antiburgueses e anticapitalistas do fascismo e do nazismo, presentes sobretudo quando eram movimentos, ${ }^{8}$ diziam respeito ao combate à democracia liberal - mais do que ao capitalismo propriamente dito, ao individualismo, ao materialismo, ao universalismo, enfim, aos valores consagrados pela "dupla revolução" (Hobsbawm, 1982), 
a Industrial e a Francesa. A crise dos anos que sucederam a Grande Guerra - econômica, política, moral - impunha, para os agentes de tais movimentos, uma mudança radical. À semelhança do bolchevismo que repudiavam, o fascismo e o nazismo apresentaram-se como alternativa ao modelo liberal.

Uma das mais conhecidas fotomontagens de John Heartfield retratou a tese do grande capital como sustentação do nazismo: O significado da saudação de Hitler. ${ }^{9}$ A charge foi capa em 1932 da Arbeiter-Illustrierte-Zeitung (AIZ), revista semanal ilustrada do Partido Comunista da Alemanha (KPD). 0 artista alemão, militante do partido, mostrou um Hitler que, ao erguer o braço na conhecida saudação, recebe de um burguês posicionado atrás dele, além de representado em escala maior do que a do Führer, um maço de notas de Reichsmarks, moeda alemã desde 1924.

Entre os pioneiros da tese de que o fenômeno nazista era fruto do grande capital contrarrevolucionário, destaca-se a obra de Franz Neumann, Behemoth: structure and practice of National Socialism. Ao publicá-la em 1942, no exílio norte-americano, o jurista e cientista político alemão de origem judaica e ligado ao Partido Social Democrata da Alemanha (SPD) expôs em detalhes o apoio do grande capital ao Estado nazista. Segundo Neumann, integrante do marxismo florescente na Escola de Frankfurt, tal vinculação desconstruía a ideia de uma revolução nacional-socialista, que os próprios nazistas defenderam, ao menos no início do regime. Neumann reconheceu, contudo, que o regime não tinha intenção de reconstruir qualquer ordem anterior à República de Weimar (Neumann, 2009: 104-105). Logo, que o nazismo não queria recuar ou conservar, e sim avançar.

No mesmo ano em que veio a público o livro de Neumann, Herbert Marcuse, que, com a morte do amigo, organizou seus escritos inacabados, sentenciou: depois da exaustiva pesquisa de Neumann, não se podia mais falar em revolução nacional socialista (Marcuse, 1998).

0 trabalho de Neumann e o juízo categórico de Marcuse, também de origem judaica e pensador da Escola de Frankfurt, não puseram fim, entretanto, à discussão. A relação entre nazismo e capitalismo continuou suscitando debate e, atualmente, a historiografia apresenta interpretações mais nuançadas do que os autores marxistas supuseram num primeiro momento (Ayçoberry, 1982; Rousso, 1991a; Paxton, 2007).

Se as três ideologias - bolchevismo, fascismo e nazismo - repudiaram o liberalismo, legado da Revolução Francesa, incorporaram, por sua vez, o ideal de criar a nova sociedade e o novo homem, inerente ao conceito de revolução desde 1789. No século XX, a Rússia bolchevique e logo a URSS estalinista, assim como os regimes diametralmente opostos da Itália fascista e da a Alemanha nazista, tentaram, cada um a seu modo, realizar essa utopia. 
Mussolini, formulador da matriz na qual outras experiências fascistas se espelharam, incluindo o nazismo, em autobiografia de 1928 refere-se à revolução fascista como promotora de uma grande ruptura. Egresso da esquerda socialista, na qual militara por anos, inclusive como editor do jornal socialista Avanti!, levou o conceito de revolução - e sua positividade - para o campo da direita. Por meio dela, se daria a modernização da economia e o reconhecimento dos direitos do povo na Itália. A transformação pretendida seria tal que o regime não deixaria qualquer atividade pública ou privada da população alheia às ingerências do Estado. Nesse sentido Mussolini enalteceu, em discurso proferido em 1935, o caráter totalitário do fascismo (Silva, 2000: 119). Renato Bertelli, escultor futurista, traduziu essa ideia em arte. Em Perfil contínuo do Duce, busto em $360^{\circ}$, de 1933 , onde quer que o observador se posicione, será acompanhado pelo líder fascista. Desde os anos 1930, por sinal, a ideia de totalitarismo foi incorporada por análises sobre a ascensão de tais regimes, e nas décadas seguintes foi sistematizada como conceito, ganhando destaque nos anos da Guerra Fria.

Se os Estados fascista e nazista alcançaram o controle absoluto das relações sociais - pressuposto do conceito de totalitarismo -, eis, no entanto, matéria de amplo debate historiográfico na segunda metade do século XX. Diversos trabalhos mostraram as incompletudes e os limites da ambição totalitária, nesses regimes, assim como no soviético (Peschanski, 1991; Hermet, Hassner, Rupnik, 1999; Traverso, 1998, 2001). Há décadas os historiadores usam o conceito de totalitarismo não para reafirmar uma hipertrofia do Estado que teria levado à dissolução da sociedade civil, mas para especificar aqueles regimes que tentaram fazê-lo, diferentemente de ditaduras e regimes autoritários tradicionais. Como na conhecida versão mussoliniana, Tudo no Estado, nada fora do Estado, nada contra o Estado. ${ }^{10}$ Ou, como na versão nacional socialista, Um povo, um Império, um líder. ${ }^{11}$

A Opera Nazionale Balilla, na Itália, e a Juventude Hitlerista, na Alemanha, oferecem exemplos evidentes do projeto de formar cidadãos fascistas e nacional-socialistas, desde a infância até o início da vida adulta. A família nuclear, a escola convencional e a educação religiosa tornavam-se secundárias, nessa lógica, para a formação do indivíduo. 0 mesmo vale para a Opera Nazionale Dopolavoro e a Força pela Alegria, que atuavam, na Itália e na Alemanha, respectivamente, junto aos trabalhadores em momentos de lazer ou ócio. No extremo da intenção totalitária, voltada para a normatização das condutas individuais de foro íntimo e das relações conjugais, as Leis de Nuremberg, de 1935, interditaram casamentos racialmente mistos e criminalizaram relações sexuais entre arianos e não arianos. 0 objetivo, no caso, era purificar a raça germânica, apostando na utopia de um novo homem exclusivamente alemão no país. Em 1938, a Itália fascista, tentando se aproximar da Alemanha, promulgou sua 
legislação antissemita, embora até então não tivesse deflagrado discriminação racial alguma contra quaisquer grupos em seu projeto de revolução. ${ }^{12}$

Quanto à adoção do conceito de revolução como bandeira ideológica dos totalitarismos em foco, vale lembrar, antes de tudo, que Hitler nunca se identificara com a esquerda, muito menos com a esquerda revolucionária, à diferença de Mussolini. Em Minha luta, mistura de autobiografia com projeto político, ele não qualifica a transformação desejada para a Alemanha como revolução. ${ }^{13}$ Escrito na prisão em 1924 e publicado no ano seguinte, o livro é, pode-se dizer, contemporâneo da autobiografia do ditador italiano. Nele, revolução é um termo execrado, associado diretamente à revolução alemã spartaquista de 1918-1919 (Hitler, 2001). Mais tarde, as lideranças do Partido Nacional Socialista dos Trabalhadores Alemães (NSDAP) - e o próprio Hitler - passaram a falar na revolução nacional socialista. Da mesma forma como assumiu símbolos da esquerda, como a cor vermelha, o $1^{\circ}$ de maio etc., o nazismo incorporou a revolução em seu ideário, agregando o sentido positivo nela presente desde o século XIX no meio operário de esquerda. Nessa metamorfose, a revolução tornava-se nacional, em oposição à revolução internacional. Ainda assim, revolução.

Se os nazistas falavam na revolução nacional socialista, em discurso proferido no congresso do NSDAP em Nuremberg em setembro de 1934, Hitler declarou que tal revolução, em curso desde a chegada do partido ao poder no ano anterior, se encerrava naquele momento (Hitler apud Neumann, 2009). Esta declaração pode ser compreendida em função de dois eventos capitais ocorridos naquele ano: 1) a chamada ala socialista do Partido, aglutinada nas SA sob a liderança de Ernst Röhm, fiel à bandeira antiburguesa do movimento, havia sido expurgada na Noite dos longos punhais, ${ }^{14}$ 2) o presidente da República, Hindenburg, morrera em agosto e, na sequência, o Führer passara a acumular as funções de chanceler e presidente da República, com a anuência de quase $90 \%$ da população, convocada para plebiscito sobre a matéria.

No entanto, paradoxalmente, foi no momento em que se desvencilhou da ala antiburguesa abrigada nas SA que o partido, a começar por Hitler, avançou em sua revolução nacional socialista. Aos olhos dos historiadores que a interpretam como tal, a revolução havia apenas entrado no seu segundo ano, em 1934. ${ }^{15}$ Aliás, a afirmação do Führer, em Nuremberg, parece ter sido mais um efeito de retórica, pois ele mesmo e outras lideranças do regime seguiram falando em revolução para se referir às mudanças que implementavam. Assim, a palavra revolução, que na Alemanha fora por décadas um monopólio dos socialistas e comunistas, passou a integrar o vocabulário político do nazismo para qualificar as transformações - sem dúvida radicais, em numerosos aspectos - realizadas pelo regime.

0 mesmo vale para o fascismo que, desde os anos 1920, não apenas se apropriou como ressignificou o conceito por meio da fórmula revolução fascista. A grande inovação esteve 
na ultrapassagem do nacional em favor do universal na formulação do conceito de fascismo, inseparável, segundo o Duce, do conceito de revolução. Mussolini, em 1928, insistia na ideia de que o fascismo não era "um artigo de exportação", realçando o nacionalismo contra 0 internacionalismo bolchevique (Mussolini apud De Felice, 1996: 372). Nos anos seguintes, matizou a ideia, cogitando da universalidade do fascismo. Em 1934 afirmou, sem hesitar, que "desde 1929 até hoje, o fascismo, de fenômeno italiano passou a fenômeno universal" (Mussolini, 1934). ${ }^{16}$ Uma declaração certamente inspirada na ascensão do nacional socialismo ao poder na Alemanha, porém baseado em sua própria doutrina, que vinha de longe. Mas não residiria, esta oscilação vocabular, em alguma nostalgia do internacionalismo socialista, porém travestida de universalismo? O conceito de revolução, de todo modo, parece ter sido o nexo entre a militância socialista e o projeto fascista mussoliniano.

0 fato é que, seja o fascismo seja o nazismo, cada um à sua maneira moveu mundos e fundos para edificar o novo mundo e o novo homem para as respectivas nações. Nos dois casos, utopias revolucionárias.

\section{FASCISMO E NAZISMO: REVOLUÇÃO OU CONTRARREVOLUÇÃO?}

uitos historiadores enfrentaram, entretanto, a questão acerca da natureza revolucio-
nária ou contrarrevolucionária do fascismo e do nacional socialismo. Entre os autores que defendem o nazismo como revolução, duas obras publicadas na segunda metade dos anos 1960 merecem destaque: a do historiador norte-americano David Schoenbaum (1966) e a do sociólogo alemão Ralf Dahrendorf (1967). ${ }^{17}$

Segundo Dahrendorf, o nazismo completou a revolução social esgotada nas deficiências da Alemanha imperial e estagnadas nas contradições da República de Weimar. O cerne dessa revolução estava na "modernidade", por ele identificada com as estruturas e os valores das sociedades liberais e democráticas ocidentais. Evidentemente, considerada a ideologia nacional socialista, esta não seria a revolução desejada pelos nazistas. Entretanto, Dahrendorf ressalta que o processo de enquadramento das instituições e da sociedade alemã, implementado desde janeiro de 1933 até agosto de 1934, provocou, na prática, a ruptura dos laços antiliberais tradicionais (religiosos, regionais, familiares, corporativistas). Como consequência, afirma que as elites alemãs foram reduzidas a um grupo fechado e as diferentes camadas sociais ficaram rebaixadas ao mesmo estatuto, Volksgenossen ("camaradas do povo"). Assim, os nazistas apagaram todos os vestígios da ordem social erigida pelos governos autoritários e conservadores passados. As lealdades, as normas e os valores tradicionais, encarnados pelo Segundo Reich, o Império alemão (1871-1918), teriam sido 
extintos pelo nazismo, revolucionariamente, embora tal revolução tenha sido destruída pela derrota de 1945.

David Schoenbaum, por sua vez, se concentrou no período compreendido entre a chegada ao poder (1933) e o início da guerra (1939). Para ele, o Terceiro Reich realizou, nesses anos, uma dupla revolução, dupla no que diz respeito a seus meios e fins: 1) ideologicamente, a revolução nacional socialista se afirmou como uma guerra contra a sociedade burguesa e industrial; 2) contudo, na prática, para realizar-se, teve que se afinar com os interesses burgueses e industriais do país. Segundo o autor, a guerra contra a sociedade burguesa preconizada pelo nazismo só podia viabilizar-se se feita por meios industriais, agenciando os burgueses para lutar contra a burguesia. Um paradoxo, sem dúvida. Schoenbaum se ancora, neste ponto, na distinção entre a "realidade social objetiva" e a sua "interpretação". Por um lado, admite que o regime fazia o contrário do que Hitler havia prometido: aceleração da industrialização e da urbanização, concentração do capital, por exemplo. Mas, por outro lado, a imagem - "interpretação" - que o nazismo produziu dessa "realidade social", frisa Schoenbaum, era a de uma sociedade unida, mais do que qualquer outra já existente na história da modernidade alemã. Oferecendo chances a todos os alemães pertencentes à Comunidade do Povo (Volksgemeinschaft), independentemente de origens de nascimento, de classes sociais, a revolução social realizada destruiu, segundo 0 autor, as relações tradicionais entre classe e status. ${ }^{18}$ Schoenbaum conclui que, no confronto entre revolução industrial e revolução ideológica, a estrutura de classes tradicional desmoronou (Kershaw, 1997: 261).

Diferentemente do discurso ou da ideologia nazista, que valorizava as tradições, inclusive míticas, embora sem desejar jamais restaurar qualquer ordem anterior à República de Weimar, o fascismo enalteceu, desde suas origens, os valores da modernidade, do mundo industrializado dominado pelas máquinas. Ao desenvolver políticas públicas para os pequenos e médios proprietários rurais, por exemplo, pretendeu modernizar a produção com inovações tecnológicas (beneficiamento do terreno, irrigação, uso de tratores etc.), que combatessem a baixa produtividade de uma agricultura arcaica. Quando Mussolini acenava com o renascimento do antigo Império Romano, era a força da simbologia que queria mobilizar. Só aparentemente se assemelhava ao ideário nazista, cuja propaganda evocava a saga dos cavaleiros teutônicos, a medievalidade de Nuremberg etc. No entanto, a ideologia fascista esteve menos dominada pelas contradições entre o futuro a construir e a volta ao passado. Max Horkheimer, em 1943, enxergou que não era a história que interessava ao regime nazista, mas a "mitologia" (Horkheimer apud Ayçoberry, 1979: 24-25). Essa afirmativa pode ser estendida à Itália de Mussolini, quando o Duce evocava a grandeza passada de Roma. 
A relação do fascismo e do nazismo com a arte moderna de vanguarda do início do século XX expressa bem a diferença: enquanto os nacionais socialistas desprezavam o que chamaram de arte degenerada, os fascistas se identificaram e se confundiram com ela.

Zeev Sternhell, que estudou o caso italiano, defende que o fascismo foi revolucionário na medida em que produziu uma "cultura política nova e original", oposta, em sua primeira fase, às heranças do lluminismo e da Revolução Francesa. Na segunda fase, aspiraria promover a "mudança total" no campo intelectual, moral e político, visando a assegurar a perenidade de uma coletividade na qual "todas as camadas e todas as classes da sociedade" estariam integradas de forma perfeita (Sternhell, 1995: 17). Um projeto de revolução cultural radical, aos olhos do historiador israelense. 0 fascismo foi, portanto, uma "revolução de outro tipo", empenhada em mudar a natureza das relações entre indivíduo e coletividade, mantendo a procura do lucro, a propriedade privada e a economia de mercado. 0 nacionalismo fascista, que aspirou ao universalismo, como disse, baseou-se, assim, nas ideias binárias de violência e pátria; guerra e nação; ideologia nacionalista e belicista; " patriotismo revolucionário"; nacionalismo antitradicionalista e antiburguês. $\mathrm{O}$ autor conclui:

0 fascismo é o antimaterialismo nos seus contornos mais nítidos. Mas, se se ergue contra 0 liberalismo e o marxismo, ele recolhe do liberalismo o respeito pelo poder e a vitalidade dos mecanismos da economia de mercado e vai buscar no marxismo a convicção de que a violência é o motor da História, unicamente regida pelas leis da guerra (Sternhell, 1995: 21).

Renzo de Felice, por sua vez, considera que o regime fascista esteve comprometido até 1936 com as forças tradicionais (Igreja, monarquia e burguesia), embora mantivesse certa margem de autonomia em relação a elas. Com o fim da Guerra da Etiópia e a proclamação do império (maio), o Duce, enfim, rompeu o pacto tácito com as elites tradicionais e a Igreja, deslanchando uma "reviravolta totalitária", inaugurando um novo período do fascismo no poder. Portanto, somente a partir de então, segundo o autor, a Itália se tornou um Estado totalitário, rompendo com os "anos de consenso" vigentes entre 1929 e 1936. Essa passagem teve menos a ver, seguindo com De Felice, com o alinhamento da Itália à Alemanha, e sim, justamente, com revolução cultural (a revolução fascista) pretendida por Mussolini. Ela se inscrevia, ao mesmo tempo, em uma tradição nacional, contestadora da ordem social estabelecida. De Felice viu o fascismo como ponto de chegada do Risorgimento, desde o nacional jacobinismo, encarnado por Mazzini e Garibaldi, até os "intervencionistas de esquerda", que na primavera de 1915, aliados aos nacionalistas, fizeram a campanha a favor da entrada da Itália na Grande Guerra. Herdeiro de uma cultura política nacionalista e insurgente, bem como de um radicalismo de esquerda, o fascismo cresceu e avançou após a Grande Guerra, como se sabe, adensado pelos problemas resultantes da paz mutilada. 
A "reviravolta totalitária" significou, para De Felice, o retorno ao primeiro fascismo, ou seja, ao fascismo movimento, anterior à chegada ao poder. Em suas origens, o fascismo fora essencialmente republicano, antirreligioso e antiburguês; revolucionário, progressista, modernista. Curiosamente, nos anos em que vários autores viram uma Itália buscando se aproximar de uma Alemanha prestes a se lançar na conquista da Europa, De Felice enxergou uma volta ao tempo em que o fascismo se opunha ao nacional socialismo, considerado então um "pessimismo trágico". 0 totalitarismo na Itália fascista não teria sido, nessa perspectiva, uma escolha da burguesia visando a reforçar privilégios e poder, tal como interpretaram os marxistas, mas uma iniciativa contra ela, ao menos discursivamente, mesmo que a burguesia italiana fosse a grande beneficiada do processo. A revolução cultural fascista teria como objetivo quebrar a hegemonia da classe dirigente tradicional, julgada incapaz de presidir os destinos da nação por sua vocação individualista, hedonista, cosmopolita (De Felice, 1976, 1996, 1981).

Daí a necessidade, ainda segundo De Felice, de o regime garantir a sua perenidade, ancorando-se não mais na "adesão passiva do maior número", mas no "consenso ativo" de um povo regenerado pelo "costume/hábito" fascista. Passava-se, portanto, da fase do consenso para a fase totalitária. Essa iniciativa implicou remodelar o corpo social e moldar o homem novo, recorrendo-se a todos os meios: escola, esporte, movimentos de juventude, preparação militar e, enfim, a guerra (De Felice, 1974, 1981; Milza, 2001). ${ }^{19}$

Diversos autores negaram frontalmente, como disse, o caráter revolucionário dos regimes fascista e nazista. É o caso do historiador britânico lan Kershaw, centrado no caso específico da Alemanha, que se opõe à concretude de uma revolução nacional socialista, embora considere simplista a redução do nazismo à condição de um "produto direto e um simples instrumento das forças capitalistas e reacionárias" (Kershaw, 1997: 268). Para ele, o regime não transformou as estruturas sociais. A exemplo de Martin Broszat, afirma que as grandes ambições nazistas estavam "na transformação das percepções subjetivas da realidade e não propriamente na realidade" $: 20$

o problema da Alemanha residia, no fundo, nas atitudes, nos valores e nas mentalidades; são eles, portanto, que os nazistas se esforçaram para modificar, substituindo os pertencimentos de classe, religiosos e regionais por uma consciência nacional exacerbada capaz de entusiasmar o povo alemão em vista do combate a vir e de mobilizá-lo quando a guerra eclodisse. Não se tratava de confrontar os ideais estreitos da classe média inferior das pequenas cidades, mas de forjar um povo à imagem de um exército - disciplinado, resistente, fanaticamente convencido e pronto para morrer pela causa. A 'comunidade nacional' não era um slogan destinado a transformar as estruturas sociais, mas o símbolo de uma nova consciência de si. Inculcar este tipo de valores no povo alemão implicava, antes de tudo, valorizar a propaganda e não a política social (Kershaw, 1997: 271). 
Kershaw conclui que a " concepção da mudança social negativa (liquidação das organizações da classe operária, discriminação aumentada contra as minorias)" repousava, portanto, em uma "revolução das mentalidades" (1997: 271-2). No entanto, pondera que, a curto ou médio prazo, essa revolução das mentalidades revelar-se-ia ilusória, diante do apego que os alemães mantiveram em relação às Igrejas (protestante e católica), a uma região ou a uma classe, a despeito dos esforços do regime para quebrá-lo. Diante da incapacidade de conduzir uma "autêntica revolução social" (1997: 272; grifos no original), o regime teria intensificado, cada vez mais, a perseguição aos "estereótipos negativos", termo usado por Hans Mommsen (apud Kershaw, 1997: 272).

Para Kershaw, o "impacto do nazismo sobre a sociedade alemã" não estaria nas transformações que teria realizado no país e sim na "natureza intrinsecamente destrutiva do regime" (1997: 282). Tendo minado a antiga ordem social e obstinado pela política de rearmamento, guerra e expansionismo, o nazismo provocou um turbilhão de destruições que acabaria por tragar até os representantes da ordem estabelecida, conduzindo à derrota total do país em 1945. Segundo Kershaw, com o colapso do regime, tornou-se possível, no pós-guerra, o aparecimento de um Estado capitalista diferente na parte ocidental, e de uma "autêntica revolução social" na parte oriental do país. Para o historiador, a revolução provocada pelo nazismo a leste foi justamente aquela iniciada quando o regime foi derrotado. Na parte ocidental,

o desaparecimento da aristocracia, a bancarrota dos antigos chefes militares e de seus ideais germano-prussianos, as intermináveis colunas de refugiados provenientes do Leste, a divisão do país, os imperativos da reconstrução e da política de 'reeducação' conduzida pelos Aliados provocaram uma ruptura com o passado, ao lado da qual as transformaç̧ões sociais sob o Terceiro Reich parecem insignificantes (Kershaw, 1997: 282-3).

Robert 0. Paxton busca de certa forma conciliar as análises que opõem os conceitos de revolução e reação na interpretação dos fascismos, tratados pelo autor no plural. ${ }^{21} 0$ historiador norte-americano reconhece neles aspectos ao mesmo tempo revolucionários e conservadores, quando não reacionários.

Apesar das "mudanças de dimensões estarrecedoras, [os regimes italiano e alemão] deixaram em grande medida intactas a distribuição da propriedade e a hierarquia econômica e social (numa oposição diametral à acepção que o termo revolução assumiu a partir de 1789)" (Paxton, 2007: 234-5). Portanto, a revolução desejada pelos fascismos não seria de ordem socioeconômica, sobretudo após a ascensão ao poder, ao costurar alianças que os afastavam dos discursos radicais dos primeiros tempos. A revolução seria, antes de tudo, uma "revolução da alma" e uma "revolução na posição ocupada por seu povo na hierarquia do 
poder mundial" (Paxton, 2007: 235). Para realizá-la, suas lideranças precisavam do exército, da vitalidade econômica da ordem e da propriedade. Os projetos fascistas, que se viam como regeneradores de seus países, também implicavam "mudanças na natureza da cidadania e na relação dos cidadãos com o Estado que foram as mais fundamentais já vistas desde as revoluções democráticas dos séculos XVIII e XIX" (Paxton, 2007: 236).

É nesta chave que Paxton explica a abolição dos direitos individuais e a subordinação completa do indivíduo ao Estado; a supressão do pacto firmado entre os cidadãos, base do Estado liberal, em favor de uma relação vertical de poder entre o Estado e os cidadãos; o desaparecimento, enfim, do Estado de direito. Paxton destaca, assim, as rupturas institucionais promovidas pelos fascismos em relação às democracias liberais.

As maiores concessões dos fascistas ao chegarem ao poder, tendo em vista o discurso radical antiburgês e anticapitalista da fase anterior a esse momento, segundo Paxton, poderiam ser identificadas, justamente, nas políticas econômicas, tanto na Itália como na Alemanha, favoráveis ao grande capital. Contudo, elas teriam sido praticadas pelos agentes da nova ordem, exclusivamente, como meio para se chegar ao fim pretendido. É por essa razão que Paxton afirma que, nos fascismos, "a política sobrepujou a economia" (2007: 240).

Buscando um ponto de equilíbrio, como disse acima, entre as interpretações acerca da natureza revolucionária ou contrarrevolucionária dos fascismos, Paxton define: "O fascismo foi revolucionário em suas concepções radicalmente novas da cidadania e das formas de participação individual na vida comunitária. Foi contrarrevolucionário, contudo, com respeito aos projetos tradicionais da esquerda, tais como as liberdades individuais, os direitos humanos, 0 devido processo legal e a paz internacional."

Em conclusão, defende ele que:"os regimes fascistas funcionavam como um epóxi: um amálgama de dois agentes muito diferentes entre si, o dinamismo fascista e a ordem conservadora, ligados pela inimizade em comum pelo liberalismo e pela esquerda e pela disposição compartilhada de destruir a qualquer preço seus inimigos comuns" (Paxton, 2007: 244, ambas as citações).

Robert Gellately, em Apoiando Hitler, refere-se ao longo de todo o livro à "revolução nazista" para tratar das transformações implementadas no país desde a chegada de Hitler ao poder (Gellately, 2011). A pertinência do conceito parece de tal forma evidente ao historiador que este sequer procura justificá-lo.

Em La révoltion culturelle nazie, livro recentemente publicado, Johann Chapoutot propõe um interpretação original para o debate. Segundo o historiador, para entender a concepção de revolução cultural é preciso voltar à definição de revolução tal como os próprios nazistas a empregaram, ou seja, ao sentido pré-revolucionário do termo. A revolução nazista, 
acredita, não pretendeu projetar um novo mundo para o futuro ou para alhures, mas o retorno à origem. Retomava-se, portanto, o sentido que a palavra tinha antes da Revolução Francesa. Esse sentido teria sido usado pelos nazistas menos para explorar o prestígio e a carga mobilizadora da palavra revolução, mas sobretudo para marcar a ruptura com 1789. "'Apagar 1789 da história', diz, significava apagar até o sentido revolucionário da palavra 'revolução'" . Assim,

a revolução cultural nazista é uma operação arqueológica: livrar a raça germânica dos sedimentos culturais que se depositaram sobre ela durante alienações sucessivas. Voltar à verdade do ser germânico, tal como ele se exprime nas tribos descritas por Tácito, mas também na Grécia e em Roma, aquelas tribos das origens, de antes, evidentemente, das alienações e das mestiçagens (Chapoutot, 2017: 275).

O nacional socialismo não buscava um hipotético homem novo, interpreta Chapoutot, mas o "homem antigo". A raça germânica, aos olhos dos ideólogos e profissionais engajados na revolução (médicos, biólogos, historiadores policiais etc.), tendo em vista o estágio em que se encontrava a história, deveria se reencontrar por meio de um "salto para trás". Caso contrário, pereceria. Daí, "o projeto de revolução cultural é, igualmente, uma promessa, uma promessa de libertação" (Chapoutot, 2017: 275). Tratava-se de livrar-se das ideias do "velho homem judaico-cristão, humanista, universalista e liberal" , mas também de voltar ao "homem novo", não aquele a ser criado, mas o das origens, "o primeiro". Somente assim seria possível "sair da história", uma história que só causara sofrimento aos germânicos. Daí, o historiador reafirma: "o nazismo não é nem projeção em direção à utopia de um homem novo nem reação desejando o retorno a um estágio anterior da história" (Chapoutot, 2017: 276). A fórmula "Reich de mil anos", substituindo desde 1938 a denominação Terceiro Reich, expressaria esse "desígnio absoluto". "Sem ordinal para um projeto cardinal". A revolução cultural nazista seria, então, a saída - ou a libertação - da história.

No que diz respeito à bibliografia brasileira, a discussão sobre o caráter revolucionário ou reacionário do fascismo e do nazismo não aparece sistematizada, e sim dispersa na produção de autores dedicados à temática do fascismo e do nazismo.

Hélgio Trindade, na década de 1970, publicou Integralismo, sobre o fascismo brasileiro na década de 1930, inspirado no modelo italiano. 0 livro tornou-se referência para o tema desde então. Para o cientista político, o fascismo europeu e sua versão brasileira foram reações contrarrevolucionárias, embora definissem a si mesmos como revolucionários (Trindade, 1974).

Já na década de 1980, estudando o Estado Novo de Getúlio Vargas, Alcir Lenharo publicou Sacralização da política (1986). Na obra, dedica-se a compreender a construção 
do ideal de trabalhador por meio da propaganda oficial, tendo em vista o controle social por parte do regime fundado em 1937, referenciado nas ideologias totalitárias da Europa da época. No mesmo ano, Lenharo lançou o livro Nazismo, "o triunfo da vontade", no qual fica mais evidente sua percepção acerca da temática que aqui nos interessa. Nele, o autor demonstra ser sensível à capacidade que o nacional socialismo teve de fascinar não somente as massas descontentes e desorganizadas, mas também os trabalhadores alemães organizados. Para tanto, utiliza a bibliografia produzida pelos exilados da Escola de Frankfurt, os quais, recorrendo à psicologia, buscavam interpretar o fenômeno. Lenharo enxerga as relações entre arte e política recorrendo a autores como Jean-Michel Palmier, ainda hoje pouco conhecido no país. Considerando-se o momento em que foi escrito, o trabalho é bastante inovador. Com tal abordagem, Lenharo aproxima-se inúmeras vezes da perspectiva da revolução cultural produzida pelos nazistas. Entre tantos exemplos, com Wilhelm Reich, cita Otto Strasser, um dos líderes da chamada ala mais à esquerda do partido, ao criticar os marxistas: " 'Seu erro básico é que vocês rejeitam ou ridicularizam a alma e a mente, e não compreendem que estas movem tudo'" (Strasser apud Lenharo, 1986: 15). Entretanto, as conclusões de Lenharo acabam na contramão do que ele mesmo escreve, interpretando o projeto nazista como contrarrevolucionário.

Maria Helena Capelato, em Multidões em cena, livro publicado em 1998, faz a história comparada das comemorações e festas cívico-esportistas varguistas e peronistas que tiveram como referência aquelas realizadas na Itália fascista e na Alemanha nazista. Transformadas em espetáculos, esses regimes usaram-nas como meio para a difusão da propaganda, valendo-se do imaginário social difuso em suas sociedades. Capelato também explora o poder dessas iniciativas visando à adesão popular e à transformação da ordem vigente. Entretanto, não afirma o caráter revolucionário das matrizes ideológicas inspiradoras dos regimes de Vargas e Perón. Em 1995, a autora publicara o artigo "O nazismo e a produção da guerra", em que já mostrara o impacto dos símbolos e valores enraizados na sociedade alemã, ritualizados na mobilização popular por meio da propaganda. Com esse recurso, o nacional socialismo buscava realizar seu "ideal revolucionário" (Capelato, 1995: 86). Como em Multidões em cena, a autora vê a natureza revolucionária do nazismo na autoimagem que seus ideólogos elaboraram, sem, no entanto, identificar tais regimes com revolução. Nos dois textos, Capelato não chega a explicitar a polêmica reação-revolução.

Em 2000, Francisco Carlos Teixeira da Silva publicou "Os fascismos", interpretando o fenômeno como revolução, não apenas como autoconstrução de seus contemporâneos, mas também como produção de conhecimento da realidade passada. Com Pierre Ayçoberry, o autor defende que "o fascismo é aquilo que ele faz e diz sobre si mesmo" (Ayçoberry apud 
Silva, 2000: 127). A "teia social de novo tipo" que os fascismos pretenderam criar, destruindo a "ordem social liberal-burguesa", estaria no seio da "Revolução Fascista" (Silva, 2000: 141). E conclui:

Não é uma revolução [a fascista] que deveria alterar as condições materiais do indivíduo, promover a distribuição da riqueza social; tratava-se de salvar o coletivo, a comunidade, da aniquilação ante o outro, o estranho/estrangeiro, assumindo assim um caráter reativo e defensivo, não, como muitos propõem, diante do socialismo em expansão, mas, diretamente, em face do perigo de fragmentação ante a hegemonia liberal (Silva, 2000: 162).

Por fim, cito João Fábio Bertonha, com vasta produção sobre a influência do fascismo italiano e sua influência no Brasil. Em artigo de 2015, o autor refere-se à interpretação comumente encontrada na bibliografia, segundo a qual o fascismo teria sido um movimento conservador e/ou reacionário. Entre os autores marxistas, conservador, pois surgido no combate contra a revolução socialista. Já a qualificação reacionário apareceria como sinônimo de conservadorismo, inclusive de retorno ao passado. 0 historiador destaca, entretanto, como aliás se viu acima, que o "encanto fascista pelo passado" foi antes recurso para mobilizar as massas no "projeto político moderno, e não para pregar a volta ao passado". Para ele, o fascismo não seria "nem reacionário nem conservador, mas ligado a estes por parentesco ideológico e conveniência política..." (2015: 206). A diferença do fascismo em relação aos movimentos e regimes reacionários ou conservadores também residia no fato de o fascismo nascer como um movimento moderno, propondo um "futuro diferente" (2015: 207). Tampouco em Bertonha a dupla negação ("nem reacionário nem conservador") se desdobra na caracterização do fascismo como revolucionário, salvo, uma vez mais, na imagem que construiu de si. 0 autor destaca, por outro lado, que "ele [o fascismo] não rompe [...] com a ordem capitalista e suas bases ideológicas [que], ao final, são as da direita: ordem, hierarquia, desigualdade" (Bertonha, 2015: 207).

\section{O FASCISMO E O NAZISMO COMO REVOLUÇÕES DE DIREITA}

a Alemanha, as mudanças assumiram um radicalismo e uma rapidez extraordinários.
Em poucos meses o Reich nacional socialista suprimiu todos os partidos políticos e o NSDAP tornou-se partido único, confundindo-se com o Estado. A cultura política socialista mais sólida do movimento operário internacional ruiu, levando junto seus partidos, sindicatos e associações. Grande parte da geração antinazista de artistas, intelectuais e políticos desapareceu do país, no exílio ou na prisão. A Alemanha de Goethe, Schiller, Mann devia dar lugar ao 
novo mundo. Fogueiras de livros queimavam séculos de cultura. Obras de arte eram retiradas dos museus. 0 país de Planck e Einstein assistiu ao racismo arrogar-se como ciência. Estabeleceram-se leis antissemitas no país europeu onde ocorrera a maior assimilação de judeus desde o século XIX. Expurgaram-se dos serviços públicos e dos setores privados da economia os alemães de origem judaica, confiscando-se-lhes bens, propriedades, cidadania. Os direitos civis foram violentados e, por fim, extintos. A tradição prussiana e aristocrática, profundamente elitista e conservadora, do exército alemão, dobrou-se ao comando de um ex-cabo da Grande Guerra, elevado à condição de chefe de Estado em $1934 .{ }^{22} 0$ regime combateu sem trégua as igrejas cristãs e mesmo a fé religiosa tradicional, traço de união entre o homem e o sagrado por milênios, em qualquer parte do planeta. Desencadeou uma vigorosa política de nazificação da família e da educação. Entre consentimento e coerção (Gellately: 2011), criou-se um sistema que conquistou o apoio da maioria, reservando a polícia política (Gestapo), o Tribunal Especial, os campos de concentração e de extermínio aos exluídos por raça, posição política e comportamentos individuais, supostamente lesivos a uma germanidade idealizada. 0 projeto da Germânia, a Capital do mundo, que previa a demolição e a reconstrução de Berlim segundo a estética da ordem nazista, mudando inclusive o nome da cidade, simbolizou a nova era. A história foi substituída pela "mitologia".

Na Itália, Mussolini precisou de mais tempo para se distanciar das elites que o fizeram ascender ao poder ou mesmo romper os vínculos que o mantinham ligado a elas. Em meio a esse processo, enquadrou o proletariado no corporativismo, sistema que só reconhecia os sindicatos ligados ao Estado. Mas não exclusivamente pela força, e sim buscando o consenso, coroado com a Carta del Lavoro de 1927. No campo político, suprimiu as câmaras municipais, o senado esvaziou-se de sua função legislativa, submetido ao Partido Nacional Fascista. A natureza da cidadania mudou radicalmente, por meio de uma relação entre Estado e cidadãos que em nada lembrava a ordem liberal anterior à Marcha sobre Roma. Na economia, modernizou o campo e trouxe o pequeno e o médio proprietários rurais para o século XX. A década de 1930 consagrou o esforço para edificar a nova ordem, voltando-se para as organizações de crianças e jovens, e de lazer, que produziriam o novo homem do novo mundo. Em que pese a criação da polícia política (OVRA, Organização para a vigilância e a repressão do antifascismo) e do Tribunal Especial para julgar crimes políticos, a nova era seria construída por meio do convencimento e da repressão limitada às oposições políticas. Com Mussolini, a Itália, enfim, completou sua unificação, o Risorgimento.

0 fascismo e o nazismo romperam ou pretenderam romper com valores e referências que, por um século, haviam mudado a mentalidade do mundo ocidental. A "revolução da alma", como disse Robert O. Paxton. 
Seria a "revolução das mentalidades" menor do que revolução provocada pela luta de classes? Existiria uma "autêntica revolução social", como buscou Kershaw? Se o "impacto do nazismo sobre a sociedade alemã" está na "natureza intrinsecamente destrutiva do regime", que teria permitido, a Oeste, o surgimento de um Estado capitalista e democrático e, a Leste, uma "autêntica revolução social", não teriam sido, então, as transformações realizadas pelo Estado nacional socialista revolucionárias? Mas, afinal, o que se entende por social, nesse caso? Exclusivamente, as relações de classe e a luta entre capital e trabalho?

Continuamos, como historiadores, presos às linhas interpretativas do século XIX? Os estudos de história das mentalidades, de história cultural, das últimas décadas, nos apontam outras possibilidades interpretativas que merecem atenção.

Fascismo e nazismo: revolução ou reação? Revolução ou contrarrevolução?

Como vimos acima, os critérios usados para interpretar os movimentos e regimes fascista e nazista estão na origem da polêmica.

Os autores que discutem a questão a partir das transformações econômicas e das relações entre capital e trabalho sustentam, ou se inclinam a sustentar, que tais regimes exprimiram uma reação ao avanço das esquerdas, uma contrarrevolução, enfim.

Os autores que valorizaram - e não apenas mencionaram - o impacto das rupturas institucionais, a remodelação dos direitos civis e políticos e a construção de uma nova identidade nacional, no plano cultural e das mentalidades coletivas, admitiram, ou tenderam a admitir, o caráter revolucionário desses regimes.

Em resumo, o fascismo e o nazismo promoveram revoluções de direita no contexto do entre-guerras. Perpetraram autênticas cirurgias no campo da cultura dos respectivos países, combinando propaganda e perseguições; destroçaram os sistemas jurídicos e as instituições democráticas de representação política (mais na Alemanha do que na Itália); redefiniram radicalmente o conceito de cidadania por meio de exclusões, expropriações e interdições às minorias, reservando os direitos civis somente àqueles que preenchiam os critérios individuais para desfrutá-los, desde que observassem as regras estatais; imiscuíram-se profundamente na vida privada das famílias e indivíduos, fossem os perseguidos, fossem os apoiantes aos quais se reservava uma cidadania excludente. Ambos levaram à guerra mundial que destruiu física e moralmente a Europa, mudando o rumo da história do continente e do mundo.

As restrições ao uso do conceito revolução de direita, em particular, nas experiências históricas da Itália fascista e da Alemanha nacional socialista, estiveram - e continuam a estar - permeadas por princípios ideológicos e políticos, que limitam o conhecimento histórico.

A historiografia precisou de décadas para se diferenciar da memória acerca da Europa dominada por esses regimes para produzir conhecimento sobre esse passado, superando 
interpretações que dimensionavam de maneira exagerada as resistências e rejeitaram ou subestimaram comportamentos sociais tais como adesões, consensos, consentimentos, acomodações, omissões (Rollemberg, 2016).

Quanto tempo mais será necessário para a superação dos obstáculos políticos e ideológicos - verdadeiro tabu - que impedem o uso do conceito de revolução como categoria epistemológica?

\section{NOTAS}

1 Não estou considerando entre as revoluções burguesas o caso inglês do século XVII. Foi apenas nos anos 1940, com a interpretação marxista de Christopher Hill, que se passou a vê-lo como tal, embora nunca como exemplo clássico (Hill, 1983). Na historiografia britânica, a ruptura radical foi, durante muito tempo, tratada como Guerra Civil ou Revolução Puritana, e seu resultado institucional como Revolução Gloriosa.

2 Hobsbawm refere-se a esses historiadores como historiadores liberais, sem aspas. Ian Kershaw (1997: 267 e ss.), por sua vez, usa as aspas no adjetivo liberais.

3 Em estudo comparativo entre as Revoluções Americana e Francesa, Hannah Arendt (1988) defendeu a independência das Treze Colônias britânicas e a fundação dos EUA como o processo mais transformador.

4 No original consultado: "Centro del feudalismo en la Edad Media y país modelo de la monarquía unitaria estamental desde el Renacimiento Francia pulverizó al feudalismo en la gran revolución e instauró la dominación pura de la burguesía bajo una forma clásica como ningún otro país de Europa".

5 Usei a tradução do inglês presente em Bianchi (2014: 206).

$6 \mathrm{Na}$ frase, como "fascistas", Hobsbawm refere-se a fascistas e nazistas.

7 Muitos autores usam o termo fascismos, no plural, para se referir às várias experiências históricas entre as décadas de 1920 e 1940, incluindo o nacional socialismo (Milza, 2001; Paxton, 2007; Silva, 2000). Outros preferem não fazê-lo, marcando assim a natureza racista do nacional socialismo, ausente no caso italiano (Sternhell, 1995). Tendo em vista os objetivos do presente artigo, não usarei fascismos no plural, mas fascismo e nacional socialismo.

8 Para a discussão sobre o fascismo movimento na Itália, antes da chegada ao poder, e o fascismo regime, ver De Felice (1976).

9 No original: Der Sinn des Hitlergrusses.

10 No original: Tutto nello Stato, niente al fiore dello Stato, nulla contro lo Stato.

11 No original: Ein Volk, ein Reich, ein Führer.

12 Renzo de Felice, como veremos a seguir, rejeita a tese de que as leis antissemitas do fascismo italiano foram expressão do desejo de Mussolini de aproximação com a Alemanha às vésperas do início da guerra (De Felice, 1981; Milza, 2001).

13 Ao longo do tempo, muitas foram as versões completas ou resumidas, assim como as traduções autorizadas ou não, que exigem cuidado particular do historiador ao se referir a pontos precisos da obra. Sobre o 
assunto, ver Rousso (1991b). A visão de revolução indicada acima, contudo, manteve-se constate nas várias edições.

14 Ernst Röhm, às vésperas de cair, referiu-se à revolução nacional socialista como estágio seguinte à chegada ao poder, ocorrida em 1933 (Röhm, 1934).

15 Veremos, adiante, a historiografia que defende a tese das revoluções fascista e nazista.

16 No original: "Dal 1929 ad oggi il Fascismo da fenomeno italiano è diventato fenomeno universal".

17 As sínteses das interpretações de David Schoenbaum (Hitler's Social Revolution. Class and status in Nazi Germany, 1933-1939. Garden City, NY Doubleday, 1966) e de Ralf Dahrendorf (Society and democracy in Germany. New York \& London: W. W. Norton \& Company, 1967), que se seguem estão baseadas no estudo historiográfico de lan Kershaw sobre o assunto (Kershaw, 1997, 2a ediç̧ão francesa, correspondente à 3a edição inglesa, atualizada, de 1993). A 1ạ edição original em inglês do livro de Kershaw é de 1985: The nazi dictatorship. Problems and perspectives of interpretation. Londres: Edward Arnold, 1985.

18 Na Juventude Hitlerista, por exemplo, para o integrante da organização nela ascender, bastavam o empenho nas atividades físicas e a fidelidade ideológica aos seus princípios (Ayçoberry, 1998: 192-210).

19 Para a discussão do consenso na Itália fascista, ver, além de De Felice (1996), Musiedlak (2010) e Dogliani (2010).

20 Kershaw refere-se à Introdução da célebre obra de Martin Broszat, Der Staat Hitlers. Grundlegung und Entwicklung seiner inneren Verfassung (München, Deutscher Taschenbuch Verlag, 1969), que não consta das traduções para o inglês - The Hitler State. The foundation and development of the internal structure of the Third Reich (London, 1981) - e para o francês - L'État hitlérien. L'origine et l'évolution des structures du Troisième Reich (Paris: Fayard, 1986).

21 Sobre o uso do termo fascismos, no plural, ver nota acima.

22 Em que pesem as articulações de resistência aos nazistas no interior das forças armadas (Rollemberg: 2016).

\section{REFERÊNCIAS BIBLIOGRÁFICAS}

ARENDT, Hannah. Da revolução. São Paulo: Ática; Brasília: Ed. UnB, 1988.

AYÇOBERRY, Pierre (org.). Franz Neumann Behemonth. Dossier. Le Débat. Set.-out. 1982/4, n. 21. Paris: Gallimard, 1982.

. La question nazie. Les interprétations du national-socialisme. 1922-1975. Paris: Seuil, 1979.

La société allemande sous le Ille Reich. 1933-1945. Paris: Éditions du Seuil, 1998.

BERTONHA, João Fábio. Sobre fascismos e ditaduras: a herança fascista na formatação dos regimes militares do Brasil, Argentina e Chile. Revista de História Comparada. V. 9, n. 1, p. 203-231, Rio de Janeiro, 2015.

BIANCHI, Álvaro. Lincoln, Marx e a guerra civil nos Estados Unidos. Outubro, ㄲo 22, 2- semestre de 2014, p. 201-226.

BRAUDEL, Fernand. História e Ciências Sociais. A longa duração. In: Escritos sobre a História. São Paulo: Perspectiva, 1992, p. 41-78. 
BROSZAT, Martin. L'État hitlérien. L'origine et l'évolution des structures du Troisième Reich. Paris: Fayard, 1986. CAPELATO, Maria Helena. 0 nazismo e a produção da guerra. Revista da USP. São Paulo (26), 82-93, jun/ ago 1995.

. Multidões em cena. Propaganda política no varguismo e no peronismo. Campinas: Papirus, 1998.

CHAPOUTOT, Joahann. La révolution culturelle nazie. Paris: Gallimard, 2017.

DAHRENDORF, Ralf. Society and democracy in Germany. New York \& London:W. W. Norton \& Company, 1967.

DE FELICE, Renzo. Mussolini il Duce, I. Gli anni del consenso. 1929-1936. Turim: Einaudi, 1996 (1a ed de 1974).

. Mussolini il Duce, II, Lo Stato totalitario, 1936-1940, Turim: Einaudi, 1981.

. Explicar o fascismo. Lisboa: Edições 70, 1976.

DOGLIANI, Patrizia. Consenso e organização do consenso na Itália fascista. In: ROLLEMBERG, Denise e QUADRAT, Samantha (orgs.). A construção social dos regimes autoritários. Legitimidade, consenso e consentimento no século XX. Vol.1 (Europa). Rio de Janeiro: Civilização Brasileira, 2010.

GELLATELY, Robert. Apoiando Hitler. Consentimento e coerção na Alemanha nazista. Rio de Janeiro: Record, 2011.

HERMET, Guy, HASSNER, Pierre e RUPNIK, Jacques (orgs.), Totalitarismes. Paris: Economica, 1999 (1a ed. 1984).

HILL, Christopher. A Revolução Inglesa de 1640. 2ª ed. Lisboa: Presença, 1983 (1ª ed inglesa de 1940).

HITLER, A. Minha luta. São Paulo: Centauro, 2001.

HOBSBAWM, Eric J. Faire une "révolution bourgeoise". Revue d'Histoire Moderne et Contemporaine. Paris: 2006/5 (no 53-4bis), p. 51-68.

. A era dos extremos. O breve século XX. 1914-1991. 2ª ed. São Paulo: Companhia das Letras, 1995. . A era das revoluções. 1789-1848. 4a ed. Rio de Janeiro: Paz e Terra, 1982.

KERSHAW, lan. Qu'est-ce que le nazisme? Problèmes et perspectives d'interpretation. 2a ed. Paris: Gallimard, 1997. Cap. 7: "Le Ille Reich: une 'réaction ou une 'révolution' sociale?, p. 251-283.

The nazi dictatorship. Problems and perspectives of interpretation. Londres: Edward Arnold, 1985.

LENHARO, Alcir. Sacralização da política. Campinas: Ed Unicamp/ Papirus, 1986.

Nazismo. 0 "triunfo da vontade". São Paulo: Ática, 1986 (Série Princípios).

MARCUSE, Herbert. State and individual under national socialismo. In Technology, war, and fascism. Textos reunidos por Douglas Kellner. Vol. 1. Londres/ Nova York: Routledge, 1998.

MARX, Karl. El 18 Brumario de Luis Bonaparte. Madrid: Fundación Frederico Engels, 2003.

. O Manifesto do Partido Comunista. In: MARX, K. e ENGELS, F. Obras escolhidas. Vol. 1. São Paulo: Alfa-Omega, s/d.

. On America and the Civil War. New York: McGraw-Hill, 1972. 
MILZA, Pierre. Les fascismes. Paris: Seuil, 2001.

MUSIEDLAK, Didier. 0 fascismo italiano: entre consentimento e consenso. In: ROLLEMBERG, Denise e QUADRAT, Samantha (orgs.). A construção social dos regimes autoritários. Legitimidade, consenso e consentimento no século XX. Vol.1 (Europa). Rio de Janeiro: Civilização Brasileira, 2010.

MUSSOLINI, Benito. My autobiography. Nova York: Charles Scribner's Sons, 1928.

Discorso pronunciato dal Duce alla Seconda Assemblea Quinquennale del Regime. Roma, 18 marzo 1934-XII E. F. In: XV Annuale della fundazione dei fasci di combattimento. Roma: 1934. Disponível em: http:// www.lorien.it/x_inni/pg_canzoni-d/Disc_BM/Discorso_BM_1934-03-18.html (consulta em 24/1/2017).

NEUMANN, Franz. Behemoth: structure and practice of National Socialism, 1933-1944. Chicago: Ivan R. Dee, 2009.

PAXTON, Robert O. A anatomia do fascismo. São Paulo: Paz e Terra, 2007.

PESCHANSKI, Denis. Le concept du totalitarisme. In: ; POLLAK, Michael; ROUSSO, Henry (orgs.). Histoire Politique et Sciences Sociales. Questions au XXè siècle. Paris/Bruxelas: IHTP/Editions Complexes, 1991.

RÖHM, Ernst. Die nationalsozialistische Revolution und SA. Discurso pronunciado para o corpo diplomático e os representantes da imprensa estrangeira, em Berlim, 18 de abril de 1934.

ROLLEMBERG, Denise. Resistência. Memória da ocupação nazista na França e na Itália. São Paulo: Alameda, 2016.

ROUSSO, Henry. Le grand capital a-t-il soutenu Hitler? In: L'Histoire. L'Allemagne de Hitler. 1933-1945. Paris: Seuil, 1991a.

"Mein Kampf", le best-seller des années trente. In: L'Histoire. L'Allemagne de Hitler. 1933-1945. Paris: Seuil, 1991b.

SCHOENBAUM, David. Hitler's Social Revolution. Class and status in Nazi Germany, 1933-1939. Garden City, NY Doubleday, 1966.

SILVA, Francisco Carlos Teixeira da. Os fascismos. In: REIS, Daniel Aarão, FERREIRA, Jorge, ZENHA, Celeste (orgs.). O século XX. Rio de Janeiro: Civilização Brasileira, 2000.

STERNHELL, Zeev. Nascimento da ideologia fascista. Lisboa: Bertrand Editora, 1995.

TRAVERSO, Enzo. Le totalitarisme. Histoire et apories d'un concept. In: L'Homme et la société, n. 129, 1998. Regards sur I'humanitaire. pp. 97-111.

(ed.). Le totalitarisme. Le XXe siècle en débat. Paris: Seuil, 2001.

TRINDADE, Hélgio. Integralismo, o fascismo brasileiro na década de 30. São Paulo: Difel, 1974. 
